\title{
Regulation of ITGA3 by the dual-stranded microRNA-199 family as a potential prognostic marker in bladder cancer
}

Takashi Sakaguchi, Hirofumi Yoshino, Masaya Yonemori, Kazutaka Miyamoto, Satoshi Sugita, Ryosuke Matsushita, Toshihiko Itesako, Shuichi Tatarano, Masayuki Nakagawa and Hideki Enokida

Correction to: British Journal of Cancer (2017) 116, 1077-1087. doi:10.1038/bjc.2017.43; published online 21 March 2017

There are errors in the data in Figure 6C and Supplementary Figure 2 showing the Kaplan-Meier analyses of the overall survival of bladder cancer patients from the TCGA cohort. The original figures had shown that the low $m i R-199 a-1, m i R-199 a-2$, and $m i R-$ $199 b$ expression groups $(n=202)$ had significantly lower overall survival rates than patients with high expression of these premiRNA groups $(n=202)$ (Figure $6 \mathrm{C})$ and that patients in the high ITGA3 expression group $(n=134)$ exhibited lower overall survival rates compared with those in the low expression group $(n=134)$ (Supplementary Figure 2).
There was an error in the categorisation of the patients who died, and they were categorised as 'censored', although they should have been 'uncensored'. Reanalysis of the data found no significant differences in overall survival between high and low expression groups (amended Figure 6C and amended Supplementary Figure 2).

The amended Figure 6 is presented here, and the amended Supplementary Figure 2 is available online.

This work is published under the standard license to publish agreement. After 12 months the work will become freely available and the license terms will switch to a Creative Commons AttributionNonCommercial-Share Alike 4.0 Unported License.

Supplementary Information accompanies this paper on British Journal of Cancer website (http://www.nature.com/bjc) 
A
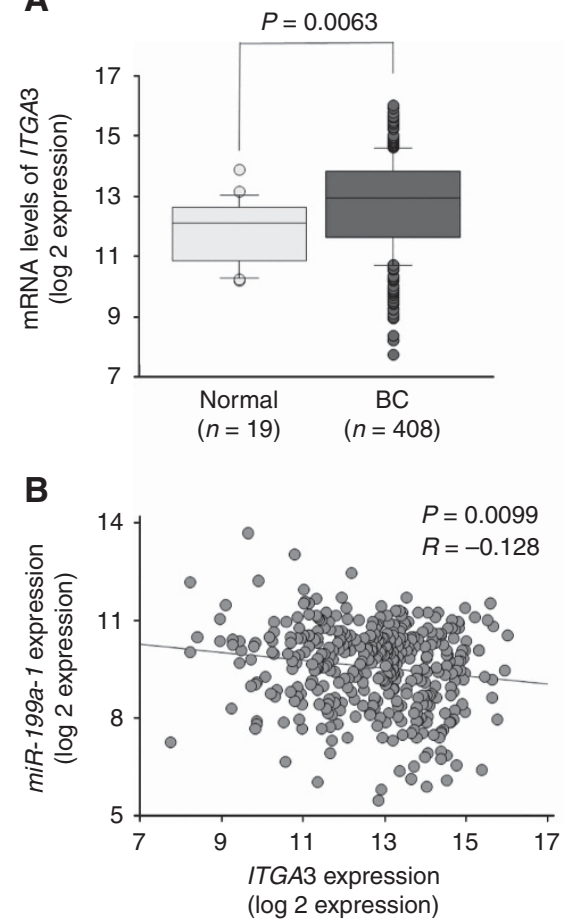

C

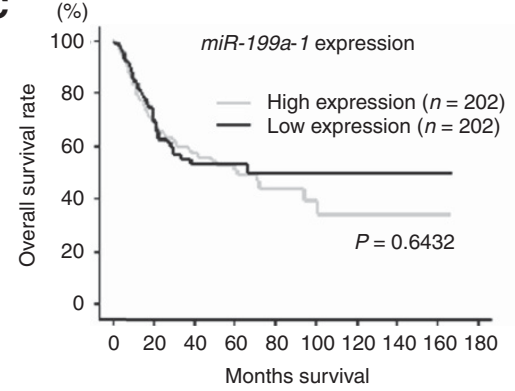

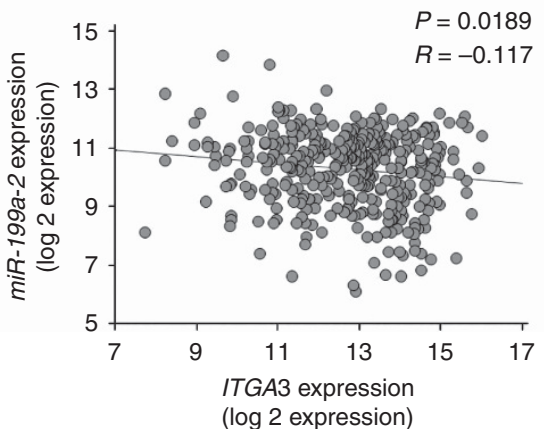
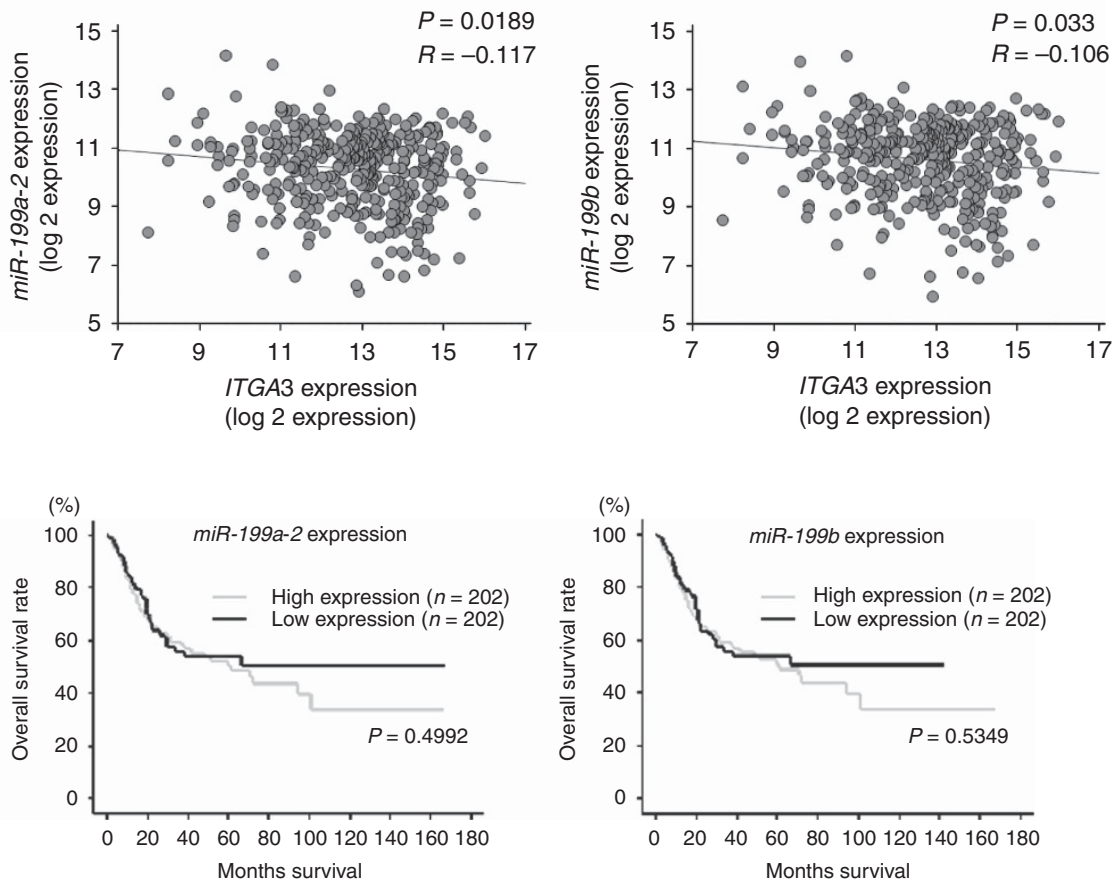

Figure 6. Analysis of the clinical BC specimens in TCGA data sets. (A) The expression level of ITGA3 mRNA was significantly upregulated in BC tissues compared with that in normal bladder tissues $(P=0.0063)$. (B) Negative correlations between ITGA3 expression and miR-199a-1, miR-199a2, and miR-199b expression in BC tissues $(P=0.0099, R=-0.128 ; P=0.0189, R=-0.117$; and $P=0.033, R=-0.106$, respectively). (C) Kaplan-Meier analysis showed no significant differences in overall survival rates between the groups of low and high expression levels of miR-199a-1, miR-199a2, and miR-199b frosm the TCGA cohort. 